\title{
MUJAHID VERSUS TERORIS
}

\author{
Ilyas Supena \\ UIN Sunan Kalijaga Yogyakarta \\ e-mail: ilyas_supena@yahoo.co.id
}

\begin{abstract}
War of opinions about the victims of Bali blast in public media was observed in two national newspaper, Republika and Kompas. Although the both newspapers are of national level, but in fact the request to be objective in informing opinions toward all community class and groups is some-thing difficult to achieve. This is based in the idea that every communication action contains any interrest-the more in mass media. In the side of Republika the execution of Amrozi seen as universal humanity problem, meanwhile for Kompas it only seen as local case that is related to the persons involved in the incident. Republika provides enough room for developing the discourse on jihad and terorism in order to build a counter opinion on the news that oftenly offense Amrozi meanwhil Kompas convines it self for not to involve in the discourse of theology.

Perang opini tentang korban ledakan Bali di media massa diamati di dua surat kabar nasional, yaitu Republika dan Kompas. Walaupun kedua surat kabar tersebut berskala nasional, namun dalam kenyataannya tuntutan untuk obyektif dalam menyampaikan opini kepada masyarakat merupakan hal yang sulit. Ini didasarkan pada gagasan bahwa setiap tindakan komunikasi mengandung kepentingan. Di pihak Republika ekskusi Amrozi dipandang sebagai masalah kemanusiaan universal, sementara bagi Kompas ekskusi tersebut hanya dipandang sebagai kasus lokal yang terkait dengan pribadi yang terlibat dalam kejadian tersebut. Republika memberikan ruang yang cukup bagi pengembangan diskursus mengenai jihad dan terorisme dalam rangka untuk membangun opini imbangan terhadap berita-berita yang seringkali menentang Amrozi sementara Kompas membatasi diri untuk tidak masuk ke dalam diskursus teologi.
\end{abstract}

Keywords: Republika, Kompas, bom Bali, Amrozi, counter pendapat 


\section{A. Pendahuluan}

Seorang wartawan idealnya menuliskan hasil liputannya secara objektif. Namun dalam kenyataannya tidak mudah, sebab wartawan sendiri merupakan bagian integral dari kelompok sosial tertentu yang sudah pasti memiliki sistem nilai (value system) tertentu pula. Dalam konteks yang lebih luas, wartawan juga terikat oleh kepentingan bisnis serta ideologi pemilik modal. Berdasarkan pertimbangan tersebut, maka posisi wartawan (termasuk media massa yang menaunginya) berada dalam dua posisi yang saling berseberangan. Di satu sisi, media merupakan tempat menuangkan dan menyampaikan pandangan semua pihak yang berkepentingan secara objektif, tetapi pada saat yang sama media juga seringkali berperan sebagai subjek yang mengkonstruksi realitas dengan segenap kepentingan, ideologi dan pemihakan yang melekat padanya. ${ }^{1}$ Dalam dua posisi demikian, maka tarik-menarik antara tuntutan objektivitas dan kepentingan subjektivitas menjadi sulit untuk dihindari. Hal ini tampak dalam penggunaan istilah "Lumpur Lapindo" dan "Lumpur Sidoarjo" yang keduanya sama-sama merujuk pada lumpur panas dari PT. Lapindo Brantas, perusahaan pertambangan milik keluarga Bakrie.

Pertarungan wacana juga berlangsung dalam hubungannya dengan eksekusi mati Amrozi, Imam Samudra, dan Mukhlas (selanjutnya disebut Amrozi cs) yang telah dilaksanakan pada 8 November 2008 lalu. Polemik ini berkembang bukan hanya dalam aspek pelaksanaan eksekusi mati itu sendiri apakah sesuai dengan Hak Asasi Manusia ataukah tidak, melainkan juga dengan aspek kesesuaiannya dengan hukum pidana Islam, sebab eksekusi dengan cara tembak mati tidak dikenal dalam Islam. Selain itu, polemik juga berlangsung dalam hubungannya dengan status kematian Amrozi cs tersebut, apakah mati sebagai seorang mujahid (shuhadā') atau mati sebagai seorang teroris (mati konyol). Dari polemik ini kemudian berkembang ke dalam polemik mengenai penafsiran makna jihad itu sendiri. Sebagian ada yang mengatakan bahwa jihad itu identik dengan perang, sebagian lagi mengatakan bahwa jihad di zaman sekarang ini lebih berhubungan dengan upaya mengentaskan kemiskinan, kebodohan dan sejenisnya. ${ }^{2}$

\footnotetext{
1 Eriyanto, Analisis Wacana: Pengantar Analisis Teks Media, (Yogyakarta: LkiS, 2006), h. 36.

2 Donny Irawan, "Penyesatan Intelektual dan Penyesatan Politik," http://kepritoday. com/content/view/15265/36/, Jumat, 14 November 2008 | 10:08:23, diakses tanggal 15 Desember 2008.
} 
Tidak bisa dipungkiri, perang opini kemudian berlangsung di media massa, baik antara umat Islam yang pro dan umat Islam yang kontra, maupun antara umat Islam itu sendiri dengan umat non-Muslim yang menjadi korban peledakan bom Bali. Perang opini ini antara lain berlangsung di dua buah koran nasional; yakni Kompas dan Republika. Sebagai sebuah media massa, Kompas dan Republika dituntut bersikap objektif dalam menyuarakan opini semua kelompok. Akan tetapi, menurut teori kritis objektivitas pemberitaan di media massa tersebut merupakan sesuatu yang sulit untuk diraih, sebab setiap tindakan komunikasi senantiasa mengandung kepentingan-lebih-lebih komunikasi melalui media massa. Berdasarkan latar belakang masalah tersebut, beberapa pertanyaan yang muncul kemudian adalah sebagai berikut: (1) Bagaimanakah pemberitaan Kompas mengenai eksekusi mati Amrozi cs? (2) Bagaimanakah pemberitaan Republika mengenai eksekusi mati Amrozi cs? (3) Bagaimanakah pemberitaan Kompas atas pandangan tokoh agama mengenai status kematian Amrozi cs? (4) Bagaimanakah pemberitaan Republika atas pandangan tokoh agama mengenai status kematian Amrozi cs?

\section{B. Teks sebagai Respon atas Situasi}

Penelitian yang bertema "Mujahid versus Teroris (Analisis Wacana Kritis Pemberitaan Kompas dan Republika terhadap Eksekusi Mati Amrozi cs.)" ini selanjutnya akan menggunakan pendekatan kritis untuk mengungkap makna dan kepentingan yang bersembunyi di balik teks media. Pandangan teori kritis ini berangkat dari sebuah asumsi bahwa media bukanlah entitas yang netral, tetapi bisa dikuasai oleh kelompok dominan. Media memiliki kemungkinan besar dikuasai oleh kelompok-kelompok yang memegang kekuasaan. Bagi teori kritis, teori selalu diasumsikan memiliki nilai emansipatoris karena ia bersifat kritis dan curiga terhadap masyarakat, sistem organisasi sosial, sistem kepercayaan dan seterusnya. Semua ini dicurigai sebagai sesuatu yang irrasional yang menempatkan individu di bawah pengaruh dominasi faktor sosial tertentu yang bisa jadi tidak disadari individu itu sendiri. Teori kritis lalu berusaha menolong dan menjadikan masyarakat agar lebih rasional dan mampu keluar dari belenggu irrasionalitas zamannya. ${ }^{3}$ Dengan misi emansipatoris yang di-

3 Bambang A, Sipayung, “Teori Kritis Versus Hermeneutika: Debat Habermas dan Gadamer," Majalah Filsafat Driyarkara, Tahun XXIII No 1, h. 41.

Walisongo, Volume 20, Nomor 1, Mei 2012 
emban teori kritis, teori kritis berusaha mengarahkan masyarakat menuju masyarakat yang lebih rasional melalui refleksi diri. Transformasi sosial ini perlu diperjuangkan melalui dialog-dialog emansipatoris. Hanya melalui jalan komunikasi dan bukan melalui jalan dominasi inilah diutopikan terwujudnya suatu masyarakat demokratis liberal, yaitu masyarakat yang berinteraksi dalam suasana komunikasi yang bebas dari penguasaan. ${ }^{4}$

Berangkat dari misi emansipatoris ini, teori kritis hendak menembus realitas sosial sebagai fakta sosiologis untuk menemukan kondisi-kondisi yang bersifat transendental dan melampaui data empiris. Jadi, teori kritis tidak mau berhenti pada fakta-fakta objektif seperti yang dianut teori-teori positivistis, melainkan berusaha menembus sistem rasionalitas yang bersembunyi di balik fakta objektif tersebut. Dengan kata lain, teori kritis berusaha melakukan "dialektika" antara pengetahuan yang bersifat transendental dan yang empiris.

Sebuah karya tulis, termasuk teks media, pada umumnya merupakan respon terhadap situasi yang dihadapi oleh penulis dalam ruang dan waktu tertentu. Akibatnya, seorang pembaca mungkin akan salah paham jika ia tidak memperhatikan sisi psikologis dan status sosial pengarangnya (wartawan), sebab pengarang adalah people who carry the inescapable baggage and conviviality of the human condition. ${ }^{5}$ karena itu, seorang pembaca harus berprasangka sebelum membaca teks ini, disebabkan karena every person comes to a text carrying his or her own questions and expectations and that it would be absurd to demand from any interpreter the setting aside of his/her subjectivity and interpret a text without pre-understanding and the questions initiated by it. ${ }^{6}$

Keharusan berperasangka ini dimotori terutama oleh Nietzsche, Marx dan Freud yang ketiganya dalam tradisi hermeneutika dijuluki sebagai the master of prejudice. Menurut mereka, perasaan, pikiran, tindakan dan pembicaraan serta tulisan seseorang tanpa disadari mesti dikendalikan oleh kekuatan bawah sadarnya (sub-conscious). Dalam pandangan Nieetzshe, dalam diri seseorang selalu terdapat dorongan laten untuk memperoleh kekuasaan atas orang lain. Menurut Freud, kekuatan libido yang obsesif dengan prinsip

\footnotetext{
${ }^{4}$ Budi Hardiman, Kritik Ideologi..., h. 21.

${ }^{5}$ Farid Esack, Qur'an, Liberation and Pluralism: An Islamic Perspective of Interreligius Solidarity Against Oppression, (Oxford: Oneworld, 1997), p. 50.

6 Ibid., p. 51.
} 
kenikmatan jasmani yang ditandai dengan seks seseorang kuat mengendalikan pikiran dan perilaku seseorang. Adapun Marx yakin bahwa status sosial ekonomi dan politik akan mewarnai cara berpikir seseorang. Oleh karena itu, agar pembaca tidak terbawa oleh subjektivitas pengarangnya, maka dalam menelaah teks diperlukan counter-prejudice, artinya pembaca perlu curiga atau kritis terhadap diri sendiri dan terhadap teks, agar terjadi wacana yang cerdas dan seobjektif mungkin antara paham pembaca dan penulis. ${ }^{7}$

Jadi, dalam memahami sebuah teks media, seseorang dituntut untuk berusaha memahami pribadi seorang pengarang yang melahirkannya serta situasi dan tradisi sosial tempat ia hidup dan baru kemudian memahami format teks yang ditulisnya. Tuntutan tersebut karena sebuah teks bisa saja menipu pembacanya ketika pembaca tidak mengenal lebih jauh siapa pengarangnya.

\section{Pemberitaan Kompas dan Republika terhadap Eksekusi Mati Amrozi cs}

Wacana eksekusi mati terhadap pelaku bom Bali I telah muncul pasca peristiwa peledakan bom tersebut pada tahun 2002. Akan tetapi, berita hangat mengenai proses eksekusi ini menjadi lebih intensif pada tahun 2008, saat menjelang detik-detik pelaksanaan hukuman mati tersebut. Republika dan Kompas merupakan salah satu media massa nasional yang mengekspos pemberitaan seputar eksekusi mati Amrozi cs tersebut. Materi berita yang muncul pada Harian Republika dapat dilihat pada berikut:

Tabel 1.

Materi Berita Harian Republika terkait Eksekusi Amrozi cs

\begin{tabular}{|c|l|}
\hline Tanggal & \multicolumn{1}{c|}{ Topik Berita } \\
\hline 18 Juli 2008 & Australia Menanti Datangnya Hari Eksekusi Amrozi cs \\
\hline 22 Juli 2008 & Eksekusi Amrozi tak Bisa Gunakan Syariat Islam \\
\hline 10 Oktober 2008 & Eksekusi Amrozi cs Tetap Tahun Ini \\
\hline 13 Oktober 2008 & Penundaan Eksekusi Amrozi Cederai Rasa Keadilan \\
\hline 24 Oktober 2008 & Opini Publik Australia Beragam Soal Amrozi dkk. \\
\hline 25 Oktober 2008 & $\begin{array}{l}\text { Indonesia Harapkan Reaksi Proporsional Atas } \\
\text { Eksekusi Amrozi }\end{array}$ \\
\hline
\end{tabular}

${ }^{7}$ Ibid, p. 134.

Walisongo, Volume 20, Nomor 1, Mei 2012 


\begin{tabular}{|c|l|}
\hline 27 Oktober 2008 & $\begin{array}{l}\text { Kejagung Bantah Kedatangan Dubes Australia Terkait } \\
\text { Eksekusi Amrozi }\end{array}$ \\
\hline 28 Oktober 2008 & $\begin{array}{l}\text { Pengamat Desak Dihentikannya Akses Amrozi cs } \\
\text { kepada Media }\end{array}$ \\
\hline 30 Oktober 2008 & Depkumham tidak Beri Izin Liputan Eksekusi Amrozi \\
\hline 31 Oktober 2008 & Jelang Eksekusi Amrozi, Rakyat Bali Diimbau Tenang \\
\hline 01 November 2008 & TNI Bantu Pengamanan Eksekusi Amrozi \\
\hline 2 November 2008 & Terorisme Tetap Ada Tanpa Amrozi cs \\
\hline 3 November 2008 & $\begin{array}{l}\text { Gereja Katolik Australia Minta Indonesia Batalkan } \\
\text { Eksekusi Amrozi }\end{array}$ \\
\hline 3 November 2008 & Ba'asyir Khawatir Terjadi Bencana Besar di Indonesia \\
\hline 4 November 2008 & MUI Cilacap Siap Dampingi Amrozi dkk. \\
\hline 5 November 2008 & Tawaran Pemakaman Amrozi Dkk Ditentang \\
\hline 6 November 2008 & Jangan Kaitkan Eksekusi Amrozi cs dengan PBNU \\
\hline 7 November 2008 & Demonstrasi di Solo Menentang Eksekusi Amrozi cs \\
\hline 8 November 2008 & Eksekusi Amrozi dan Negosiasi Dini Hari yang Sulit \\
\hline 9 November 2008 & Amrozi cs Telah Dieksekusi \\
\hline 10 November 2008 & Eksekusi Mati Amrozi dkk Pelajaran bagi Umat \\
\hline 21 November 2008 & TPM Cari Fakta Eksekusi Amrozi dkk. \\
\hline
\end{tabular}

Sementara itu, topik-topik pemeritaan yang muncul di Kompas berkaitan dengan eksekusi mati Amrozi cs dapat dilihat pada tabel berikut:

Tabel 2.

Materi Berita Harian Kompas terkait Eksekusi Amrozi cs

\begin{tabular}{|c|l|}
\hline Tanggal & \multicolumn{1}{|c|}{ Materi Berita } \\
\hline 16 April 2008 & Kejagung Belum Berani Eksekusi Amrozi \\
\hline 10 Mei 2008 & TPM Kritik Rencana Eksekusi Amrozi cs. \\
\hline 23 Juni 2008 & Eksekusi Amrozi cs Disalip Dua Warga Nigeria \\
\hline 18 Juli 2008 & Eksekusi Amrozi Sah Menurut Hukum \\
\hline 19 Juli 2008 & Australia Menanti Eksekusi Amrozi cs \\
\hline 21 Juli 2008 & Amrozi Dkk Lahir Batin Siap Dieksekusi \\
\hline 22 Juli 2008 & Eksekusi Amrozi, Polda Jateng Siapkan Tiga Regu Tembak \\
\hline 24 Juli 2008 & Proses Hukum Amrozi Diintervensi Asing \\
\hline 26 Juli 2008 & Amrozi cs, Eksekusi Tunggu Keputusan Penolakan PK \\
\hline 20 Agustus 2008 & TPM Ajukan Penundaan Eksekusi Amrozi cs ke Kejagung \\
\hline 29 Agustus 2008 & Ada Permintaan Eksekusi Amrozi Ditunda \\
\hline
\end{tabular}




\begin{tabular}{|c|c|}
\hline 10 Oktober 2008 & Jaksa Agung: Eksekusi Amrozi cs Tahun 2008 \\
\hline 17 Oktober 2008 & Jaksa Agung: Saya tidak Ragu Eksekusi Amrozi cs \\
\hline 23 Oktober 2008 & Besok, Kejagung Umumkan Eksekusi Amrozi cs \\
\hline 24 Oktober 2008 & Deplu Berharap Eksekusi Amrozi cs Direspon Proporsional \\
\hline 28 Oktober 2008 & Eksekusi Amrozi cs Dijaga 1000 Personel Keamanan \\
\hline 30 Oktober 2008 & Warga Tanggapi Dingin Eksekusi Amrozi \\
\hline 31 Oktober 2008 & $\begin{array}{l}\text { Pelabuhan Tanjung Intan Dijaga Ketat: } \\
\text { Warga Tenggulun Tanggapi Eksekusi secara Dingin }\end{array}$ \\
\hline 1 November 2008 & Amrozi dkk. Tolak Pelaksanaan Eksekusi Mati \\
\hline 2 November 2008 & $\begin{array}{l}\text { Polisi Semarang Temukan } 4 \text { Kuintal Bahan Peledak: } \\
\text { Pengamanan d Sekitar Nusakambangan Superketaf }\end{array}$ \\
\hline 3 November 2008 & $\begin{array}{l}\text { Kedua Istri Amrozi dan Mukhlas Ingin Bertemu } \\
\text { Sebelum Eksekusi }\end{array}$ \\
\hline 4 November 2008 & PN Denpasar Kembali Terima Pengajuan PK Amrozi \\
\hline 5 November 2008 & $\begin{array}{l}\text { Eksekusi Mati: Tim Kejaksaan dari Jateng dan Bali } \\
\text { Kunjungi Nusakambangan }\end{array}$ \\
\hline 6 November 2008 & Belum Ada Sinyal “Jumatan” \\
\hline 7 November 2008 & $\begin{array}{l}\text { Eksekusi Mati: Nusakambangan Disterilkan dari Truk Proyek } \\
\text { hingga Senin }\end{array}$ \\
\hline 8 November 2008 & $\begin{array}{l}\text { Ponsel Dilarang Dibawa ke Nusakambangan } \\
\text { Polda Jatim Siapkan Perlindungan Keluarga Amrozi }\end{array}$ \\
\hline 9 November 2008 & Dua Helikopter Dikirim ke Nusakambangan \\
\hline 10 November 2008 & Terorisme: Polda Bali Kerahkan 6.000 Personel \\
\hline
\end{tabular}

Topik-topik pemberitaan yang muncul di kedua media massa tersebut, selanjutnya dapat diklasifikasikan ke dalam tiga perspektif: perspektif hukum dan keamanan, perspektif politik dan hubungan internasional, serta perspektif sosial-keagamaan.

\section{Teks dalam Berbagai Perspektif}

\section{Analisis Teks}

\section{a. Perspektif Hukum dan Keamanan}

Topik pemberitaan yang muncul di media Republika yang berhubungan dengan perspektif hukum dan keamanan adalah sebagai berikut: 
Tabel 3.

Materi Berita Harian Republika tentang Eksekusi Amrozi cs dalam Perspektif Hukum dan Keamanan

\begin{tabular}{|c|l|}
\hline Tanggal & \multicolumn{1}{|c|}{ Materi Berita } \\
\hline 18 Juli 2008 & Australia Menanti Datangnya Hari Eksekusi Amrozi cs. \\
\hline 10 Oktober 2008 & Eksekusi Amrozi cs Tetap Tahun Ini \\
\hline 13 Oktober 2008 & Penundaan Eksekusi Amrozi Cederai Rasa Keadilan \\
\hline 30 Oktober 2008 & Depkumham tidak Beri Izin Liputan Eksekusi Amrozi \\
\hline 01 November 2008 & TNI Bantu Pengamanan Eksekusi Amrozi \\
\hline 8 November 2008 & Eksekusi Amrozi dan Negosiasi Dini Hari yang Sulit \\
\hline 9 November 2008 & Amrozi cs Telah Dieksekusi \\
\hline 21 November 2008 & TPM Cari Fakta Eksekusi Amrozi dkk \\
\hline
\end{tabular}

Sedangkan topik pemberitaan Kompas yang berhubungan dengan perspektif hukum dan keamanan adalah sebagai berikut:

Tabel 4.

Materi Berita Harian Kompas tentang Eksekusi Amrozi cs dalam Perspektif Hukum dan Keamanan

\begin{tabular}{|c|l|}
\hline Tanggal & \multicolumn{1}{|c|}{ Materi Berita } \\
\hline 16 April 2008 & Kejagung Belum Berani Eksekusi Amrozi \\
\hline 10 Mei 2008 & TPM Kritik Rencana Eksekusi Amrozi cs \\
\hline 23 Juni 2008 & Eksekusi Amrozi cs Disalip Dua Warga Nigeria \\
\hline 18 Juli 2008 & Eksekusi Amrozi Sah Menurut Hukum \\
\hline 19 Juli 2008 & Australia Menanti Eksekusi Amrozi cs \\
\hline 22 Juli 2008 & Eksekusi Amrozi, Polda Jateng Siapkan Tiga Regu Tembak \\
\hline 26 Juli 2008 & Amrozi cs, Eksekusi Tunggu Keputusan Penolakan PK \\
\hline 20 Agustus 2008 & TPM Ajukan Penundaan Eksekusi Amrozi cs ke Kejagung \\
\hline 29 Agustus 2008 & Ada Permintaan Eksekusi Amrozi Ditunda \\
\hline 10 Oktober 2008 & Jaksa Agung: Eksekusi Amrozi cs Tahun 2008 \\
\hline 17 Oktober 2008 & Jaksa Agung: Saya Tidak Ragu Eksekusi Amrozi cs \\
\hline 23 Oktober 2008 & Besok, Kejagung Umumkan Eksekusi Amrozi cs \\
\hline 28 Oktober 2008 & Eksekusi Amrozi cs Dijaga 1000 Personel Keamanan \\
\hline 1 November 2008 & Amrozi dkk Tolak Pelaksanaan Eksekusi Mati \\
\hline 2 November 2008 & $\begin{array}{l}\text { Polisi Semarang Temukan 4 Kuintal Bahan Peledak } \\
\text { Pengamanan d Sekitar Nusakambangn Superketaf }\end{array}$ \\
\hline
\end{tabular}




\begin{tabular}{|c|l|}
\hline 4 November 2008 & PN Denpasar Kembali Terima Pengajuan PK Amrozi \\
\hline 5 November 2008 & $\begin{array}{l}\text { Eksekusi Mati: Tim Kejaksaan dari Jateng dan Bali Kunjungi } \\
\text { Nusakambangan }\end{array}$ \\
\hline 6 November 2008 & Belum Ada Sinyal “Jumatan” \\
\hline 7 November 2008 & $\begin{array}{l}\text { Eksekusi Mati: Nusakambangan Disterilkan dari Truk Proyek } \\
\text { hingga Senin }\end{array}$ \\
\hline 9 November 2008 & $\begin{array}{l}\text { Ponsel Dilarang Dibawa Ke Nusakambangan } \\
\text { Polda Jatim Siapkan Perlindungan Keluarga Amrozi }\end{array}$ \\
\hline 10 November 2008 & Dua Helikpter Dikirim ke Nusakambangan \\
\hline
\end{tabular}

Melihat topik-topik pemberitaan Republika dan Kompas tersebut, tampak wacana yang digulirkan Kompas dalam kaitannya dengan perspektif hukum dan keamanan jauh lebih lengkap dibandingkan dengan wacana yang digulirkan Republika. Kompas banyak memilih tema-tema yang berhubungan dengan pergulatan dan dinamika hukum pelaksanaan eksekusi mati Amrozi cs tersebut. Kompas memberitakan perdebatan hukum antara Jaksa dan TPM (Tim Pembela Muslim) yang menjadi kuasa hukum Amrozi cs serta perjalanan pengadilan hingga proses peninjauan kembali (PK), sampai lahirnya ketetapan hukum yang bersifat tetap terhadap terpidana mati Amrozi cs. Perjalanan pengadilan Amrozi cs tersebut dijelaskan dari waktu ke waktu secara detail oleh Harian Kompas. Bukan hanya itu, Kompas juga secara detail memberitakan proses persiapan jaksa dan pihak keamanan dalam upaya persiapan pelaksanaan eksekusi tersebut.

Sementara itu, Harian Republika menghindari pemberitaan yang menyangkut aspek yuridis. Topik-topik yang muncul adalah "Australia Menanti Datangnya Hari Eksekusi Amrozi cs," "Eksekusi Amrozi cs Tetap Tahun Ini," "Penundaan Eksekusi Amrozi Cederai Rasa Keadilan," "Depkumham tidak Beri Izin Liputan Eksekusi Amrozi," "TNI Bantu Pengamanan Eksekusi Amrozi," "Eksekusi Amrozi dan Negosiasi Dini Hari yang Sulit," "Amrozi cs Telah Dieksekusi" dan "TPM Cari Fakta Eksekusi Amrozi dkk". Harian Republika tidak menampilkan penjelasan secara detail mengenai proses hukum dan persiapan eksekusi mati Amrozi cs.

Selain topik-topik yang diberitakan kedua harian media massa tersebut, kecenderungan kedua media massa tersebut dalam memberitakan eksekusi mati Amrozi cs dalam perspektif hukum dan keamanan dapat dilakukan de- 
ngan menganalisis secara kritis materi pemberitaan kedua media massa tersebut. Salah satunya adalah topik pemberitaan Republika "Australia Menanti Datangnya Hari Eksekusi Amrozi cs" dan topik pemberitaan Kompas "Australia Menanti Eksekusi Amrozi cs".

Dalam pemberitaan Republika "Australia Menanti Datangnya Hari Eksekusi Amrozi cs," wacana yang dikembangkan adalah repson warga Australia terhadap pelaksanaan eksekusi mati Amrozi cs. Materi pemberitaan didasarkan pada sumber media lokal yang gencar memberitakan bahwa Amrozi cs dalam waktu dekat akan dieksekusi mati oleh Tim Kejaksaan RI.

Strategi wacana yang digunakan Republika selanjutnya dapat dianalisis melalui langkah-langkah berikut:

\section{1) Strategi Representasi}

Republika mengawali materi berita tersebut dengan mengatakan: "Publik Australia kini menanti datangnya hari pelaksanaan eksekusi terhadap Amrozi bin H. Nurhasyim, Ali Ghufron, dan Imam Samudera, tiga terpidana mati yang ikut bertanggung jawab atas tewasnya 202 orang, termasuk 88 orang warga negara Australia, dalam insiden Bom Bali 12 Oktober 2002." Dalam materi berita tersebut, Republika tidak lupa menambahkan representasi anak kalimat "tiga terpidana mati yang ikut bertanggung jawab atas tewasnya 202 orang, termasuk 88 orang warga negara Australia, dalam insiden Bom Bali 12 Oktober 2002" untuk menegaskan sekaligus mengingatkan kembali kepada pembaca mengenai kasus yang menimpa Amrozi cs yang telah menewaskan 202 orang. Republika juga tidak lupa menambahkan anak kalimat, "termasuk 88 orang warga negara Australia" untuk mempertegas bahwa Australia merasa berkepentingan terhadap pelaksanaan eksekusi mati Amrozi tersebut. Meskipun demikian, Republika lebih suka menggunakan kata "insiden bom Bali" yang jauh lebih halus dibandingkan istiah "tragedi bom Bali". Pemilihan kata ini dalam sudut pandang teori wacana kritis bukan tanpa alasan. Boleh jadi, Republika bermaksud memperhalus dan mengemas bahasa dalam upaya menempatkan Amrozi cs bukan satu-satunya pihak yang harus dihakimi.

Selain reprsentasi anak kalimat, Republika juga menggunakan format pemberitaan yang dapat diamati dalam representasi rangkaian anak kalimat sebagai berikut: " 
Kendati umumnya publik Australia berpendapat sama dengan pemerintah Australia yang tidak ingin mencampuri keputusan sistem pengadilan dan ketatanegaraan Indonesia dalam soal hukuman mati, termasuk terhadap Amrozi cs, ada juga di antara sanak keluarga korban Bom Bali 2002 yang tidak ingin ketiga terpidana ini mati dieksekusi.

Surat kabar "The Australian" mengutip hasil wawancara ABC dengan Brian Deegan yang kehilangan putranya, Josh, dalam peristiwa 2002 itu mengatakan ia tidak menginginkan Amrozi cs dipandang sebagai "martir" atau "orang suci" di mata para pengikutnya."

Statemen berita tersebut merupakan bagian dari strategi wacana yang dilakukan Republika. Republika mencoba menawarkan wacana penjelasan kontras terhadap wacana yang berlaku umum bagi warga Australia. Secara cerdik Republika telah membuka ruang wacana kepada pembaca bahwa hukuman mati bukan solusi terbaik dalam mengatasi terorisme. Dalam hal ini, Republika mengatakan bahwa warga Australia-yang mayoritas korban bom Bali berasal dari negara tersebut - tidak seluruhnya sependapat dengan hukuman mati terhadap Amrozi cs. Dengan cara ini, akan muncul sebaran pendapat di masyarakat mengenai pro-kontra terhadap hukuman mati tersebut. Lebih dari itu, dengan merujuk keragaman pendapat warga Australia, Republika sebenarnya ingin mengatakan bahwa warga Australia ada yang tidak sependapat dengan hukuman mati, apalagi penduduk Indonesia.

Selain itu, Republika juga mengutip ungkapan alasan ketidaksetujuan Brian Deegan yang kehilangan putranya, Josh, terhadap pelaksanaan eksekusi mati Amrozi cs. Menurutnya, eksekusi mati Amrozi cs akan menyebabkan ia dipandang sebagai "martir" atau "orang suci" di mata para pengikutnya. Secara redaksional, statemen ini menunjukkan bahwa Amrozi cs tidak layak disebut sebagai martir atau mati shahïd, tetapi di balik itu Republika ingin mengatakan bahwa ada beberapa kelompok Muslim yang memang merasa yakin bahwa Amrozi cs termasuk mujahid yang kematiannya layak disebut sebagai shuhadā' (mati shahīd).

\section{2) Strategi Relasi}

Selain aspek representasi, teks berita ini juga bisa dilihat dari aspek relasi. Bagaimana hubungan wartawan dan partisipan berita itu ditampilkan dalam teks. Dalam teks berita tersebut, relasi berlangsung antara wartawan, keluarga korban (warga Australia), dan pelaku (Amrozi cs dan Pengacaranya/TPM). 
Dalam relasi tersebut, wacana keluarga korban menjadi sangat dominan, sementara pendapat dari pelaku disembunyikan. Dalam hal ini, Republika tidak sama sekali mengutip pendapat pelaku apalagi mewawancarainya, tetapi pendapat pelaku itu dihadirkan melalui kutipan media lokal. Ini merupakan strategi wacana yang dilakukan Republika untuk menjadikan pendapat keluarga korban sebagai media untuk menyampaikan pendapat pelaku.

\section{3) Strategi Identifikasi}

Aspek identifikasi juga muncul dalam teks berita ini. Seluruh wacana yang muncul dalam teks berita ini seluruhnya mengutip sumber berita dari media lokal. Dengan cara ini, Repulika seakan-akan mengidentifikasikan dirinya sebagai bagian dari warga negara Australia dan berusaha menempatkan diri sebagai media penyaluran aspirasi warga negara Australia tersebut. Tetapi Republika juga berusaha mengungkapkan nada-nada yang "sumbang" yang berbeda dari pendapat warga negara Australia pada umumnya. Tanpa disadari pembaca, nada-nada sumbang inilah sebenarnya yang menjadi target pemberitaan Australia.

Sementara itu, Kompas menurunkan berita dengan topik "Australia Menanti Eksekusi Amrozi cs". Strategi wacana yang digunakan Kompas selanjutnya dapat dianalisis melalui langkah-langkah berikut:

\section{1) Strategi Representasi}

Dalam hal ini, Kompas memulai topik pemberitaan tersebut dengan ungkapan:

Keadilan yang telah dinanti Australia sekitar enam tahun untuk kematian 88 orang warganya di tangan para teroris di Bali 12 Oktober 2002 lalu akan segera terbayar.

Sinyal segera tibanya "dewi keadilan" bagi para korban maupun dan para orangtua, handai taulan, dan sahabat yang kehilangan mereka itu semakin jelas setelah Jaksa Agung Hendarman Supandji di Jakarta, Jumat (18/7), menegaskan bahwa eksekusi bagi Amrozi, Ali Ghufron, dan Imam Samudera sudah bisa dilaksanakan.

Dalam berita tersebut, Kompas mengatakan bahwa keadilan yang ditunggu-tunggu warga negara Australia akan segera tiba, karena-mengutip ungkapan Jaksa Agung Hendarman Supandji-eksekusi bagi Amrozi cs sudah bisa dilaksanakan. Dalam hal ini, Kompas ingin mengatakan bahwa keadilan 
akan segea datang, dan secara tegas Kompas mengatakan bahwa keadilan yang dimaksud adalah ketika pelaku bom Bali, Amrozi cs, telah dieksekusi mati.

Dalam hal ini, Kompas memilih menggunakan ungkapan metaforis "dewi keadilan". Dewi yang dalam tradisi Hindu sepadan dengan Dewa, yang berarti sesuatu yang sangat tinggi melebihi apapun, menunjukkan bahwa eksekusi mati Amrozi cs merupakan ujung dari pencarian keadilan yang dilakukukan oleh keluarga korban. Selain itu, Kompas secara tegas juga menyebut Amrozi cs sebagai pelaku teroris, sesuatu istilah yang berusaha dihindari oleh Republika.

Strategi representasi yang digunakan Kompas juga menggunakan representasi rangkaian anak kalimat sebagai berikut:

Praktis sudah tidak ada lagi celah hukum yang bisa dipakai Amrozi cs untuk bisa lepas dari jeratan kematian di ujung peluru regu tembak Polri yang sudah disiapkan kecuali keluarnya grasi dari Presiden Susilo Bambang Yudhoyono.

Namun grasi untuk ketiga orang pelaku insiden Bom Bali 2002 itu nyaris tidak mungkin karena mereka sendiri dikabarkan sudah lama menyatakan tidak berniat meminta pengampunan dari Presiden.

Dalam ungkapan tersebut, Kompas menggunakan ungkapan sarkasme "jeratan kematian di ujung peluru regu tembak Polri" yang menunjukkan sikap kemarahan Kompas-sebagai representasi warga Australia-terhadap pelaku bom Bali. Ungkapan ini semakin mempertegas keadilan yang dimaksud oleh Kompas. Bagi Kompas, hukuman mati merupakan sesuatu yang tidak bisa ditawar-tawar lagi. Untuk mendukung wacana yang digulirkan Kompas, Kompas tidak lupa mengutip ungkapan Stewart yang kehilangan putranya, Anthony, dalam serangan bom 2002 itu yang mengatakan bahwa dia akan merasa lega dan gembira jika Amrozi, Ghufron dan Imam Samudera dieksekusi hari ini atau beberapa hari mendatang.

Seperti halnya Republika, Kompas mencoba menawarkan strategi penjelasan kontras. Dalam hal ini, Kompas mengatakan:

Walaupun umumnya publik Australia berpendapat sama dengan pemerintahnya yang tidak ingin mencampuri keputusan sistem pengadilan Indonesia dalam soal hukuman mati terhadap Amrozi cs, ada juga di antara pihak keluarga korban Bom Bali 2002 yang tidak ingin ketiga terpidana ini dieksekusi mati. 
Brian Deegan yang kehilangan putranya, Josh, dalam peristiwa serangan

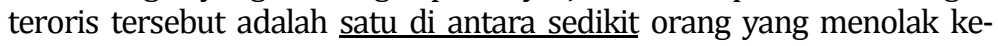
matian bagi Amrozi cs.

Surat kabar "The Australian" mengutip hasil wawancara ABC dengan Brian Deegan mengatakan dia tidak ingin Amrozi, Ghufron dan Imam Samudera dipandang sebagai martir oleh para pengikutnya.

Kutipan ini menunjukkan bahwa Kompas berusaha mengemukakan wacana bahwa meskipun mayoritas warga Australia menginginkan eksekusi mati Amrozi cs, tetapi ada juga warga Australia yang tidak sependapat. Berbeda dengan Republika, strategi wacana yang dibuat Kompas tidak berhenti di situ. Kompas segera menyatakan secara tegas bahwa yang menolak eksekusi mati itu jumlahnya sedikit, dan karenanya tidak bisa dijadikan sebagai salah satu rujukan.

\section{2) Strategi Relasi}

Selain aspek representasi, teks berita ini juga bisa dilihat dari aspek relasi. Bagaimana hubungan wartawan dan partisipan berita itu ditampilkan dalam teks. Dalam teks berita tersebut, relasi berlangsung antara wartawan, keluarga korban (warga Australia), dan pelaku (Amrozi cs dan Pengacaranya TPM). Seperti halnya Republika, dalam relasi yang muncul di Kompas, wacana keluarga korban menjadi sangat dominan, sementara pendapat dari pelaku tidak dijelaskan. Dalam hal ini, Kompas bukan hanya tidak mewawancarai pelaku, tetapi lebih dari itu Kompas bersikap ikut menghakimi pelaku itu sendiri.

\section{3) Strategi Identifikasi}

Aspek identifikasi juga muncul dalam teks berita ini. Seluruh wacana yang muncul dalam teks berita ini seluruhnya mengutip sumber berita dari media lokal. Dengan cara ini, Kompas, seperti halnya Republika, seakan-akan mengidentifikasikan dirinya sebagai bagian dari warga negara Australia dan berusaha menempatkan diri sebagai media penyaluran aspirasi warga negara Australia, dan lebih khusus lagi keluarga korban. Dalam hal ini, Kompas mengatakan:

Bagi pemerintah Australia, eksekusi terhadap Amrozi cs adalah masalah yang tidak perlu dicampuri walaupun Australia masuk dalam kelompok negara yang menolak hukuman mati. 
Sikap pemerintahan Perdana Menteri Kevin Rudd dari Partai Buruh dalam masalah eksekusi Amrozi cs yang sejalan dengan sikap pemerintahan John Howard yang digantikannya semakin menegaskan apa yang pernah disampaikan mantan Menlu Australia, Alexander Downer.

Downer mengatakan, kemarahan Australia terhadap ketiga terpidana mati kasus Bom Bali 2002 ini tidak mengenal batas. Dan keadilan yang lama ditunggu Australia itu akan segera tiba walaupun hanya Tuhan dan otoritas tertentu di Indonesia saja yang paling tahu tanggal pasti eksekusi Amrozi cs itu.

Kutipan tersebut menyiratkan bahwa Kompas hendak mementahkan kembali polemik mengenai hukuman mati terhadap Amrozi dengan mengutip pendapat Downer "Downer mengatakan, kemarahan Australia terhadap ketiga terpidana mati kasus Bom Bali 2002 ini tidak mengenal batas". Ungkapan ini menunjukkan keberpihakan Kompas kepada keluarga korban.

\section{b. Perspektif Politik dan Hubungan Internasional}

Topik-topik pemberitaan eksekusi mati di Harian Republika dan Kompas yang berhubungan dengan perspektif politik dan hubungan internasional adalah sebagai berikut:

Tabel 5.

Materi Berita Harian Republika tentang Eksekusi Amrozi cs dalam Perspektif Politik dan Hubungan Internasional

\begin{tabular}{|c|l|}
\hline \multicolumn{1}{|c|}{ Tanggal } & \multicolumn{1}{c|}{ Materi Berita } \\
\hline 25 Oktober 2008 & $\begin{array}{l}\text { Indonesia Harapkan Reaksi Proporsional Atas Eksekusi } \\
\text { Amrozi }\end{array}$ \\
\hline 27 Oktober 2008 & $\begin{array}{l}\text { Kejagung Bantah Kedatangan Dubes Australia Terkait } \\
\text { Eksekusi Amrozi }\end{array}$ \\
\hline 28 Oktober 2008 & Pengamat Desak Dihentikannya Akses Amrozi cs kepada Media \\
\hline
\end{tabular}

Tabel 6.

Materi Berita Harian Kompas tentang Eksekusi Amrozi cs dalam Perspektif Politik dan Hubungan Internasional

\begin{tabular}{|c|l|}
\hline Tanggal & \multicolumn{1}{|c|}{ Materi Berita } \\
\hline 24 juli 2008 & Proses Hukum Amrozi Diintervensi Asing \\
\hline 24 oktober 2008 & Deplu Berharap Eksekusi Amrozi cs Direspon Proporsional \\
\hline
\end{tabular}


Topik-topik yang berhubungan dengan politik dan hubungan internasional tidak sebanyak topik-topik yang berhubungan dengan perspektif hukum dan keamanan. Topik-topik di sini berkaitan dengan kedaulatan hukum negara RI yang tidak bisa diintervensi pihak asing, termasuk Australia, dalam penanganan proses hukum Amrozi cs. Terkait dengan persoalan ini, Republika menurunkan berita "Indonesia Harapkan Reaksi Proporsional Atas Eksekusi Amrozi," sedangkan Kompas menurunkan berita "Deplu Berharap Eksekusi Amrozi cs Direspon Proporsional".

Dua judul berita tersebut sepintas mengandung pengertian yang sama, padahal sesungguhnya muatan maknanya berbeda. Republika menggunakan kata "Indonesia" menunjukkan bahwa persoalan hukum atas kasus Amrozi cs merupakan bagian dari persoalan nasional dan seluruh masyarakat Indonesia, sementara Kompas menggunakan kata Deplu menunjukkan bahwa persoalan hukum atas kasus Amrozi cs merupakan bagian dari persoalan kelembagaan, yakni pengadilan Indonesia. Pemilihan kata ini sesungguhnya bukan persoalan sepele. Republika menggunakan kata Indonesia karena ingin mengatakan bahwa yang berkepentingan terhadap persoalan hukuman Amrozi cs merupakan persoalan seluruh masyarakat Indonesia. Mereka semua berkepentingan terhadap proses hukum ini. Bagi Kompas, persoalan Amrozi cs hanya persoalan pihak-pihak yang terlaibat langsung dalam proses pengadilan, dan bukan persoalan kebangsaan secara nasional.

Wacana yang dikembangkan oleh kedua media massa ini bisa dilihat dari strategi representasi; bagaimana sebuah peristiwa ditampilkan dalam teks. Strategi ini dilakukan Republika antara lain berkaitan dengan fiksi mengenai eksekusi mati Amrozi cs. Republika mengungkapkan:

Lebih lanjut Faiza mengatakan bahwa secara umum masyarakat internasional terbagi dalam dua kelompok, yaitu kelompok yang menginginkan agar eksekusi segera dilakukan dan kelompok penentang hukuman mati.

Republika mengungkapkan fakta riil yang berkembang dalam opini masyarakat Internasional, termasuk warga Australia, bahwa masyarakat internasional terbagi ke dalam dua kelompok; kelompok yang menginginkan agar eksekusi segera dilakukan dan kelompok penentang hukuman mati. Penggunaan kata "secara umum" merupakan strategi wacana yang digunakan Republika untuk menumbuhkan opini bahwa kedua kelompok ini me- 
miliki pengikut yang banyak, meskipun tidak dijelaskan mana yang lebih banyak dari yang lain. Tetapi bisa jadi cara ini dipahami oleh pembaca yang tidak kritis bahwa pendukung kedua kelompok ini sama banyaknya.

Selain itu, Republika juga menggunakan kata masyarakat Internasional (bukan warga Australia) dalam kutipan tersebut. Seperti halnya penggunaan kata "Indonesia" dalam judul berita, Republika ingin mengangkat persoalan hukuman mati Amrozi cs ini bukan persoalan lokal, atau regional tetapi ini merupakan persoalan kemanusiaan universal. Jadi ada strategi universalisasi persoalan hukuman mati Amrozi cs. Hal ini boleh jadi, karena Republika menangkap persoalan terorisme ini merupakan persoalan global menyangkut ketimpangan dan ketidakadilan dunia internasional antara Barat dan Timur.

Sementara itu, Kompas menampilkan berita dengan model ungkapan berikut:

Opini yang berkembang di Australia memang ada dua yakni ada pihak yang menanti-nanti eksekusi hukuman mati Amrozi, tetapi ada pula yang melihat dari perspektif HAM dan menentang hukuman mati karena tidak manusiawi."

Penggunaan kata "memang" dalam kutipan tersebut menunjukkan ada nada kekurangpuasan terhadap situasi dan kondisi serta sikap masyarakat Australia, mengapa mereka memiliki perbedaan sikap dalam menghadapi persoalan hukuman mati Amrozi cs. Bagi Kompas, perbedaan pendapat ini merupakan sesuatu yang tidak perlu terjadi. Kompas ingin membangun opini bahwa hukum mati merupakan harga mati bagi Amrozi cs.

Selain itu, Kompas juga menggunakan kata "Australia" (bukan masyarakat Internasional). Dalam hal ini, Kompas memandang persoalan hukuman mati Amrozi cs adalah persoalan lokal atau setidaknya bilateral antara pelaku (Indonesia) dan korban (Australia). Kompas melihat persoalan Amrozi tidak perlu diangkat sebagai persoalan internasional.

\section{c. Perspektif Sosial-Keagamaan}

Topik-topik pemberitaan eksekusi mati di Harian Republika dan Kompas yang berhubungan dengan perspektif sosial-keagamaan adalah sebagai berikut: 
Tabel 7.

Materi Berita Harian Republika tentang Eksekusi Amrozi cs dalam Perspektif Sosial-Keagamaan

\begin{tabular}{|c|l|}
\hline Tanggal & \multicolumn{1}{|c|}{ Materi Berita } \\
\hline 22 Juli 2008 & Eksekusi Amrozi tak Bisa Gunakan Syariat Islam \\
\hline 24 Oktober 2008 & Opini Publik Australia Beragam Soal Amrozi dkk. \\
\hline 31 Oktober 2008 & Jelang Eksekusi Amrozi, Rakyat Bali Diimbau Tenang \\
\hline 02 November 2008 & Terorisme Tetap Ada Tanpa Amrozi cs \\
\hline 3 November 2008 & $\begin{array}{l}\text { Gereja Katolik Australia Minta Indonesia Batalkan Eksekusi } \\
\text { Amrozi }\end{array}$ \\
\hline 3 November 2008 & Ba'asyir Khawatir Terjadi Bencana Besar di Indonesia \\
\hline 4 November 2008 & MUI Cilacap Siap Dampingi Amrozi dkk. \\
\hline 5 November 2008 & Tawaran Pemakaman Amrozi dkk. Ditentang \\
\hline 6 November 2008 & Jangan Kaitkan Eksekusi Amrozi Cs dengan PBNU \\
\hline 7 November 2008 & Demonstrasi di Solo Menentang Eksekusi Amrozics \\
\hline 10 November 2008 & Eksekusi Mati Amrozi dkk. Pelajaran bagi Umat \\
\hline
\end{tabular}

Tabel 8.

Materi Berita Harian Kompas tentang Eksekusi Amrozi cs dalam Perspektif Sosial-Keagamaan

\begin{tabular}{|c|l|}
\hline \multicolumn{1}{|c|}{ Tanggal } & \multicolumn{1}{c|}{ Materi Berita } \\
\hline 21 Juli 2008 & Amrozi dkk. Lahir Batin Siap Dieksekusi \\
\hline 30 Oktober 2008 & Warga Tanggapi Dingin Eksekusi Amrozi \\
\hline 31 Oktober 2008 & $\begin{array}{l}\text { Pelabuhan Tanjun Intan Dijaga Ketat } \\
\text { Warga Tenggulun Tanggapi Eksekusi secara Dingin }\end{array}$ \\
\hline 3 November 2008 & $\begin{array}{l}\text { Kedua Istri Amrozi dan Mukhlas Ingin Bertemu sebelum } \\
\text { Eksekusi }\end{array}$ \\
\hline
\end{tabular}

Membandingkan topik yang muncul di kedua media massa tersebut, maka tema-tema sosial keagamaan yang muncul di Harian Republika jauh lebih kaya dibandingkan dengan pemberitaan yang ada di Kompas. Tematema yang dikemukakan menunjukan adanya variasi wacana yang ingin dikembangkan Republika. Pertama, Republika menawarkan wacana hukuman mati dengan menggunakan syariat Islam berupa hukum pancung. kedua, Republika juga menawarkan keragaman pendapat mengenai hukuman mati, bahkan di kalangan kaum Gereja itu sendiri. Ketiga, Republika menawarkan wacana mengenai status teologis pelaku bom bali itu sendiri antara mujahid atau teroris. Sementara itu, Kompas tidak banyak memasuki wilayah per- 
debatan theologis pelaku bom Bali, apakah mujahid atau teroris. Kompas lebih memilih tema-tema yang berhubungan dengan kesiapan mental pelaku bom Bali dan respon masyaakat terhadap rencana hukuman mati pelau bom Bali tersebut.

Menarik untuk memahami pandangan ideologis Republika dengan membandingkan judul berita "MUI Cilacap Siap Dampingi Amrozi dkk" dan "Demonstrasi di Solo Menentang Eksekusi Amrozi cs". Kedua judul berita tersebut merupakan simbol pertarungan ideologis antara kelompok yang pro dan yang kontra terhadap hukuman mati. MUI sebagai lembaga yang dibentuk oleh pemerintah sangat mendukung kebijakan yang dilakukan pemerintah. Sementara golongan fundamentalis mencoba menentang langkah yang ditempuh oleh pemerintah.

Mensikapi fenomena tersebut, Republika menurunkan berita berjudul "MUI Cilacap Siap Dampingi Amrozi dkk." Republika memulai statemen berita tersebut dengan mengatakan:

Ulama Indonesia (MUI) Kabupaten Cilacap menyatakan siap mendampingi tiga terpidana mati kasus Bom Bali I, yakni Amrozi, Mukhlas, dan Imam Samudra, saat menjalani eksekusi.

"Kita siap mendampingi mereka sebagai rohaniwan pendamping karena merupakan tugas negara," kata Ketua Umum MUI Kabupaten Cilacap, H Dzul Bashor, di Cilacap, Selasa.

Namun hingga saat ini, kata dia, belum ada surat penunjukan dari kejaksaan kepada MUI Cilacap sebagai rohaniwan pendamping dalam eksekusi Amrozi dkk.

Disinggung mengenai kemungkinan nama-nama ulama yang akan diajukan sebagai rohaniwan jika surat penunjukan tersebut diterima, dia enggan menyebutkannya.

"Intinya, kami siap sebagai rohaniwan pendamping," katanya menegaskan.

Republika mengutip secara langsung pernyataan ketua Umum MUI Cilacap mengenai kesiapan menjadi rohaniwan pendamping. Strategi identifikasi yang menggunakan kutipan langsung, seakan-akan Republika mencoba menjadi bagian dari MUI. Tetapi berita tersebut juga menggunakan strategi representasi rangkaian anak kalimat dengan penjelasan kontras, dengan mengatakan: Namun hingga saat ini, kata dia, belum ada surat penunjukan dari kejaksaan kepada MUI Cilacap sebagai rohaniwan pendamping dalam eksekusi Amrozi dkk. Ini merupakan strategi Republika untuk membias- 
kan kesiapan eksekusi mati tersebut mengingat Kejaksaan belum menginstruksikan kepada MUI Cilacap.

Sementara itu, judul berita "Demonstrasi di Solo Menentang Eksekusi Amrozi cs," semakin mempertegas posisi Republika dalam pertarungan wacana antaa kaum fundamentalis dan liberalis. Kalimat pertama Republika mengatakan: Abu Bakar Ba'asyir memimpin aksi demonstrasi ratusan umat Islam yang tergabung dalam Jama'ah Ansharut Tauhid (JAT), Jumat siang, di bundaran Gladak, Solo, menuntut pembatalan hukuman mati terhadap Amrozi cs. Representasi kalimat "aksi demonstrasi" menunjukkan adanya penolakan masyarakat terhadap rencana eksekusi mati Amrozi cs. Kalimat ini dikuatkan dengan menyebutkan jumlah "ratusan umat Islam" yang mengikuti aksi ini.

Republika juga mengutip ungkapan Ba'asyir yang menyatakan bahwa Amrozi, Mukhlas, Ali Gufron dan Imam Samudra, bukanlah teroris seperti yang dianggap selama ini. Demikian juga Republika mengatakan: "Para demonstran membawa spanduk yang antara lain bertuliskan 'Mereka Mujahid Bukan Teroris' dan 'Menuntut Pembebasan Amrozi cs'. Ini merupakan bagian dari strategi wacana yang dilakukan Republika mengenai polemik status kematian Amrozi antara teroris dan mujahid.

Kemudian strategi relasi yang dilakukan Republika juga hanya menyebutkan pernyataan-pernyataan ketidaksetujuan para demonstran, tanpa ada wacana lain yang berkembang dalam teks berita tersebut. Ini menunjukkan adanya concern Republika pada wacana penolakan hukuman mati terhadap Amrozi.

Di pihak lain, Kompas menurunkan berita "Warga Tanggapi Dingin Eksekusi Amrozi”. Kompas memulai pemberitaannya dengan mengatakan:

Warga Desa Tenggulun, Kecamatan Solokuro, Kabupaten Lamongan, Jatim, menanggapi dingin rencana eksekusi terpidana bom Bali I Amrozi, Ali Ghufron alias Muchlas pada awal November. Bahkan mereka sama sekali tidak terkejut dengan eksekusi itu. "Ya setiap orang punya jalan hidup masing-masing. Jalan kematian setiap orang beda-beda," kata Punjadi (56) petani Desa Tengulun yang ditemui sedang membajak sawahnya, Kamis (30/10).

Representasi kalimat yang dipakai Kompas "menanggapi dingin" merupakan strategi wacana yang dilakukan Kompas untuk menyampaikan opini kepada publik bahwa proses hukuman mati terhadap Amrozi cs merupakan suatu peristiwa biasa dan tidak istimewa sehingga tidak perlu dilebih- 
lebihkan. Berbeda dengan Republika, yang menurunkan berita aksi demonstrasi yang berarti Republika menganggap eksekusi mati terhadap Amrozi cs merupakan hal yang luar biasa.

Kompas mencoba menawarkan counter wacana dengan mengutip statemen-statemen keluarga korban. Kompas misalnya menulis:

Keluarga Amrozi menyayangkan kenapa pemerintah mempercepat eksekusi. Kakak Amrozi Ustad Jakfar yang juga pengasuh Ponpes AlIslam Desa Tenggulun menuturkan kenapa terpidana mati yang sudah belasan tahun belum dieksekusi, tetapi Amrozi cs dieksekusi. Dia juga menyayangkan tidak ada lagi kesempatan membesuk ke LP Nusakambangan Cilacap, Jawa Tengah.

“Kenapa juga Bupati Lamongan sama sekali tidak memberi atensi kasus ini. Benar apa tidak warganya terlibat peledakan Bom Bali kan tetap perlu diperjuangkan bagaimana proses hukum sebaiknya," kata Jakfar.

Di sini ada upaya Kompas untuk memberi space kepada keluarga korban menyampaikan komentarnya. Tetapi counter wacana ini segera dibantah dengan statemen Kompas yang mengutip pernyataan Calon Wakil Gubernur Jawa Timur pasangan Soekarwo-Syaifullah Yusuf (Gus Ipul):

Calon Wakil Gubernur Jawa Timur pasangan Soekarwo-Syaifullah Yusuf (Gus Ipul) saat di Solokuro pada hari yang sama mengatakan biarkanlah proses hukum berjalan. "Saat ini penegakan hukum sedang baik-baiknya, besan SBY saja tersangka. Soal eksekusi terpidana mati bom Bali I, kita percayakan saja pada aparat hukum," katanya usai menyalami warga di warung pojok milik Rofiah depan kantor Polsek Solokuro.

Senada dengan Gus Ipul, kepada Kompas, Bupati Lamongan Masfuk menyatakan menyerahkan sepenuhnya proses hukum Amrozi cs kepada yang berwenang. "Soal itu saya tidak mau intervensi, tetapi saya yakin semua sudah melalui proses yang lama dan hati-hati. Kita tunggu saja seperti apa akhirnya," kata Masfuk.

Ungkapan ini menjadi kata kunci yang selama ini digunakan Kompas untuk selalu mengembalikan proses hukuman mati Amrozi cs ke pengadilan.

\section{Analisis Intertekstual}

Analisis intertekstual yang dilakukan Kompas dan Republika umumnya menggunakan model "kutipan langsung nara sumber" dan model pengandaian. Model pengandaian yang digunakan Republika antara lain kata "Australia" 
dalam judul berita "Opini Publik Australia Beragam Soal Amrozi dkk," kata "Gereja Katolik" dalam judul berita "Gereja Katolik Australia Minta Indonesia Batalkan Eksekusi Amrozi," kata "Ba'asyir" dalam judul "Ba'asyir Khawatir Terjadi Bencana Besar di Indonesia," kata "demonstrasi" dalam judul berita "Demonstrasi di Solo Menentang Eksekusi Amrozi cs".

Sementara itu, model pengandaian yang dilakukan Kompas adalah menggunakan kata " warga Nigeria" dalam judul berita "Eksekusi Amrozi cs Disalip Dua Warga Nigeria," kata "Jumatan" dalam judul berita "Belum Ada Sinyal "Jumatan," kata "Ponsel" dalam "Ponsel Dilarang Dibawa ke Nusakambangan," kata "Deplu” dalam "Deplu Berharap Eksekusi Amrozi cs Direspon Proporsional".

\section{Analisis Konteks Sosial}

Sistem demokrasi merupakan sistem pemerintahan yang mengakui dan mengembangkan proses diversifikasi kekuasaan untuk meniadakan kesenjangan hak-hak politik warga Negara serta memperluas hak warga Negara dalam bersuara dan mengemukakan berpendapat. Salah satu nilai demokrasi yang terpenting adalah menjamin tegaknya keadilan bagi seluruh warga negara. Dalam hal ini semua masyarakat mempunyai hak-hak dan kebebasan yang sama dalam berpartisipasi dan beroposisi bagi partai politik, organisasi kemasyarakatan dan perorangan serta prasarana pendapat umum semacam pers dan media massa.

Meskipun Indonesia menganut sistem demokrasi, tetapi pada masa Orde Baru, kebebasan pers diberangus atas nama keamanan dan ketertiban masyarakat. Pers harus mematuhi rambu-rambu yang dibuat negara. Sejarah juga memperlihatkan, adanya PWI (Persatuan Wartawan Indonesia) tidak membawa perubahan yang sinifikan pada pola represi itu, sebaliknya PWI justru dijadikan media yang turut mencengkeramkan kuku-kukunya pada kebebasan pers tersebut.

Rezim Orde Baru yang represif ini kemudian mengalami kehancuran pada pada peristiwa revolusi Mei 1998 dan dilanjutkan dengan pengunduran diri presiden Soeharto pada tanggal 21 Mei 1998 yang telah berkuasa selama 32 tahun. Sejak saat itu, pers Indonesia mengalami perubahan yang luar biasa dalam mengekspresikan kebebasan. Fenomena itu ditandai dengan munculnya media-media baru, cetak dan elektronik dengan berbagai kemasan dan segmen. Keberanian pers dalam mengkritik penguasa juga menjadi ciri baru 
pers Indonesia. Pers yang bebas merupakan salah satu komponen yang paling esensial dari masyarakat yang demokratis, sebagai prasyarat bagi perkembangan sosial dan ekonomi yang baik.

Kebebasan pers ini kemudian menjadi lahan bagi kelompok-kelompok ideologis tertentu untuk mengembangkan ideologinya, termasuk dalam memperbincangkan masalah jihād dan terorisme. Dalam hal ini, Republika yang menjadi surat kabar umat Islam terlibat dalam pertarungan wacana mengenai pemahaman jihād dalam Islam.

Wacana yang berkembang dalam masyarakat, jihad dipahami secara berbeda oleh dua kelompok yang berbeda (liberalis dan fundamentalis). Menurut Ma'ruf Amin, sesuai fatwa MUI, ada perbedaan yang sangat prinsip antara melakukan teror dan melakukan jihad. Jihad itu memiliki sasaran dan wilayah untuk aktivitas berperang, sehingga pelakunya disebut mujāhid, dan jika dia tewas dalam pertempuran, maka akan disebut dengan mati shahìd. Sedangkan teror adalah aktivitas yang mengganggu kedamaian suatu wilayah yang semula aman, tenteram dan damai berubah menjadi suasana yang menakutkan. Masyarakat takut karena siapa saja bisa dengan mudah menjadi sasaran teror. Banyak orang tidak berdosa menjadi korban. Belum lagi kerusakan-kerusakan yang begitu besar membutuhkan dana untuk merehabilitasinya. Ada juga dampak-dampak sosial ekonomi lain yang dialami negara yang jadi korban aksi teror. Karena teror ini membuat situasi kacau, maka pelakunya tidak bisa kita katakan mati shahìd.

Lebih lanjut Ma'ruf menjelaskan bahwa jihād dapat dipahami dalam pengertian ișlāḥ atau melakukan perbaikan umat dan lingkungan, tanpa caracara yang berupa kekerasan. Sebab yang dihadapi bangsa Indonesia saat ini adalah perang melawan kebodohan, kemiskinan, ketidakadilan, dan perang melawan korupsi. Perang seperti inilah yang membawa kemaslahatan bagi umat Islam dan umat agama lainnya di Indonesia. Selain itu, Ma'ruf juga mengatakan bahwa bangsa Indonesia sudah mempunyai kesepakatan nasional untuk hidup berdampingan dengan pemeluk agama lain secara damai. Masing-masing agama boleh mengembangkan agamanya namun dengan cara-cara yang demokratis, dengan cara menjunjung tinggi hak asasi manusia (HAM).

Berbeda dengan Ma'ruf Amin, Ustad Abu Bakar Ba'asyir mengatakan bahwa Amrozi dan kawan-kawan mati shahīd. Menurut Ba'asyir, mengalih- 
kan makna jihād dari makna asalnya, yaitu mengerahkan seluruh kemampuan untuk berperang di jalan Allah, dengan mengentaskan kemiskinan, kebodohan dan sebagainya merupakan bentuk penyesatan intelektual (taḍlīl fikri). Menurut Ba'asyir, tindakan seperti ini merupakan tindakan kriminal (jarimah), sebab dampak dari tindakan tersebut akan menyebabkan umat Islam meninggalkan ajaran Islam yang oleh Nabi Muhammad SAW disebut sebagai: "dharwah sanam al-Islām" (ujung tombak Islam). Jika umat Islam sudah meninggalkan jihad dalam arti perang atau bahkan mungkin alergi dengan jihad, maka ketika jihad dikumandangkan, mereka akan menolak jihad, dan bahkan akan mengatakan jihad itu sebagai tindakan terorisme. Padahal, hukum wajib jihad adalah qațiy, dan tidak ada ikhtiläf di kalangan ulama. Siapapun yang menolak hukum wajibnya jihad bisa dinyatakan kafir dan keluar dari Islam, sebab ia menolak hukum yang qațiy. Oleh karena itu, setiap upaya untuk mengaitkan jihad dengan terorisme juga harus ditolak. Pengaitan jihad dengan terorisme jelas berbahaya, dan ini merupakan penyesatan politik (taḍlil siyāsiy) sekaligus merupakan tindakan kriminal yang luar biasa (jarīmah kubrā).

Sementara itu, Kompas menangkap kebebasan pers yang berlangsung di era reformasi ini dengan berpergang pada pertanggungjawaban secara hukum. Di sini Kompas terlibat dalam pertarungan antara paradigma hukum positivistik dengan paradigma hukum humanistik. Di antara dua paradigm itu, Kompas cenderung lebih berpihak pada paradigma hukum positivistik.

\section{E. Kesimpulan}

Berdasarkan penjelasan tersebut, maka ada beberapa kesimpulan yang bisa diambil: (1) Bagi Republika, eksekusi mati Amrozi cs merupakan persoalan kemanusiaan universal, sementara bagi Kompas merupakan persoalan lokal atau pihak-pihak yang terlibat. (2) Bagi Kompas, eksekusi mati Amrozi cs merupakan persoalan hukum positif yang harus dijalankan, sementara Republika mengedepankan paradigma humanistik sehingga menganggap hukuman mati sebagai sesuatu yang tidak manusiawi. (3) Republika mengembangkan wacana teologis mengenai jihad dan terorisme. Dalam pertarungan wacana tersebut, Republika memberi ruang yang cukup bagi pemberitaan Ba'asyir dan kelompoknya. Upaya ini dilakukan sebagai counter wacana terhadap media massa yang sering menyudutkan Amrozi cs. 
Sementara itu, Kompas membatasi diri untuk tidak terlibat dalam wacana teologis tersebut.

Rekomendasi dari hasil penelitian ini adalah: (1) Bagi Kompas dan Republika, pemberitaan mengenai suatu fakta, termasuk dalam soal eksekusi mati Amrozi cs, hendaknya bersifat netral, seimbang, objektif dan analisis yang bersifat komprehensif, baik dilihat dari aspek hukum dan keamanan, aspek sosial politik, maupun aspek sosial keagamaan; (2) Bagi masyarakat pembaca) hendaknya bersifat kritis dalam menangkap fenomena pemberitaan di media massa, karena media massa sangat dipengaruhi oleh berbagai faktor yang ikut terlibat dalam mempengaruhi konstruk berita yang ditampilkan.[w] 


\section{BIBLIOGRAFI}

Berger, Arthur Asa, Media Analysis Techniques. California: Sage Publication, 1982. Tanda-tanda dalam Kebudayaan Kontemporer (terjemahan). Yogyakarta: Tiara Wacana, 2000.

Bignell, Jonathan, Media Semiotics, an Introduction, London: Manchaster University Press, 2001.

Chomsky, Noam dan Edward S. Herman, Manufacturing Consent: The Political Economy of the Mass Media, New York: Pantheon, 1988.

Currant, James and Michael Gurevitch, Mass Media and Society, London: Edward Arnold, 1991.

Carey, James W., Communication as Culture, Essays on Media and Society, Boston: Unwin Hyman, 1989.

Crowly, David dan David Mitchell, Communication Theory Today, Cambridge: Policy Press, 1994.

Denzin, Norman K dan Yvonna S. Lincoln, Handbook of Qualitative Research, London: Sage Publication, 2005.

Dijk, Teun A. Van, News As Discourse, Hillsdale, New Jersey: Lawrence Erlbaum Associate, 1988.

Eriyanto, Analisis Wacana: Pengantar Analisa Teks Media, Yogyakarta: LKIS, 2001.

Fairclough, Norman, Discourse and Social Change, Cambridge: Polity Press, 2006.

Analysing Discourse, Textual Analysis for Social Research, London and New York: Routledge, 2005.

Foss, Sonja K, at.al, Contemporary Perspectives on Rethoric, Illinois: Waveland, 1985.

Fiske, John, Introduction of Communication Studies. London: Routledge, 1991.

Gee, James Paul, An Introduction to Discourse Discourse Analysis, Theory and Method, London and New York: Routledge, 2005.

Gamson, Willam A dan Andre Modigliani, "Media Discourse and Public Opinion on Nuclear Power A. Constructionist Approach," Journal of Sociology, Vol. 95, No. 1. July 1989.

Griffin, EM., A First Look at Communication Theory, Boston-Toronto: McGraw Hill, 2003.

Guba, Egon. G, The Paradigm Dialog, New York: Sage Books, 1990. 
Hall, Stuart, Culture, Media dan Language, London: Routledge, 1992.

Hardiman, Budi Francisco, Kritik Ideologi: Pertautan Pengetahuan dan Kepentingan, Yogyakarta: Kanisius, 1990.

Halliday, MAK, Language as Social Semiotic, The Social Interpretation of Language and Meaning, London: The Open University Set Book, 1993.

Hamad, Ibnu, Konstruksi Realitas Politik di Media Massa sebuah Study Critical Discourse Analysis Discourse, Jakarta: Granit, 2004.

Heath, Robert L dan Jannings Bryant, Human Communication Theory and Research, Concepts, Contexts, and Challenges, Mahwah, New Jersey - London: Lawrence Erlbaum Associate Publisher, 2000.

Krippendorf, Klauss, Content Analysis, An Introduction to Its Methodolgy, Beverly Hill California: Sage Publication, 1980.

Kolakowski, Leszek, Main Currents of Marxisme III. Oxford: Clarendon Press, 1978.

Latif, Yid dan Idi Subandy Ibrahim (eds)., Bahasa dan Kekuasaan: Politik Wacana di Panggung Orde Baru. Jakarta: Mizan, 1996.

Littlejohn, Stephen, Theories of Human Communication, California: Wadsworth Publishing Company, 2002.

Lull, James, Media, Komunikasi, Kebudayaan; Suatu Pendekatan Global, Jakarta: YOI, 1998.

Littlejohn, Stephen W, Theories of Human Communication, Belmont-Toronto: Wadsworth Publishing Company, 1999.

McQuail, Dennis and Sven Windahl, Communication Models: for The Study of Mass Communication, New York: Longman, 1996.

Magnis-Suseno, Franz, Filsafat sebagai Ilmu Kritis. Yogyakarta: Kanisius, 1992. Etika Politik: Prinsip-prinsip Moral dan Dasar Kenegaraan Modern, Jakarta: Gramedia, 1991.

Mannheim, Karl, Ideology dan Uthopia. An Introduction to the Sociology of Knowledge, London: Routledge, 1979.

Mcdonnell, Diane, Theories of Discourse: An Introduction, Oxford: Basil Blackwall, 1986.

Mcquail, Dennis (ed), McQuail's Reader in Mass Communication Theory, London: Sage Publications, 2002.

Neuman, Lawrence W. Social Research Methods. London:Allyn and Bacon, 2000.

Norris, Sigrid dan Rodney H. Jones, Discourse in Action, London and New York: Routledge, 2005, 
Raboy, Marc dan Bernard Dagenais (eds)., Media, Crisis and Democracy: Mass Communication and the Disruption of Social Order, London: Sage Publication, 1995.

Reese, Stephen D,. Framing Public Life, New Jersey: Lawrence Earlbaum Publisher, 2001.

Riggins, Stephen H, The Language and Politics of Exclusion: Others in Discourse, London: Sage Publication, 1997.

Rogers, Everett. M, A History of Communication Study, New York: The Free Press, 1994.

Schiffrin, Deborah at.al, (ed.), The Handbook of Discourse Analysis. Blackwell Publishing, 2005.

Sobur, Alex, Analisis Teks Media, Suatu Pengantar Analisis Wacana, Analisis Semiotik, dan Analisis Framing, Bandung: Rosdakarya, 2001.

Saverin, Werner, Communication Theories: Origins, Methods and Uses in the Mass Media. New York:Longman, 1997.

Sen, Krishna dan David T. Hill, Media, Budaya dan Politik di Indonesia, Jakarta: PT Media Lintas Inti Nusantara, 2001.

Titscher, Stefan, atal., Methods of Text and Discourse Analysis, London-Thousand Oaks-New Delhi: Sage Publication, 2000.

Vatikionis, Michail R.J. Indonesian Politics under Soeharto, Order, Development and Pressure for Change, New York: Routledge, 1993. 